\title{
Prevalence and Risk factors for Work Related Musculoskeletal Disorders among Sonographer of Sindh Province Pakistan
}

\author{
Muneer Ahmed Junejo, Syed Muhammad Tahir, Rasool Bux Behan
}

\section{ABSTRACT}

BACKGROUND: The common work related musculoskeletal disorders (WRMDs) among medical profession are pain in neck, elbow, shoulder wrist and back. Sonographers are more vulnerable to develop WRMDs as their work demands series of awkward repetitive movements.

OBJECTIVE: To determine the prevalence of work related musculoskeletal disorders (WRMDs) and to identify factors that may contribute to musculoskeletal disorders among sonologists of Sindh Province Pakistan.

METHODOLOGY: This questionnaire based study conducted at the Department of Radiology, Liaquat University of Medical \& Health Sciences. The target population chosen for this study was sonologists from the Sind province of Pakistan. SPSS used to analyze the data, results presented as frequency for categorical variables and as mean for continuous variables. To identify predictor variable for WRMDs, multiple bivariate regression analysis was performed, the level of significant was set at $P<0.05$.

RESULTS: Among 145 participants, $\mathbf{5 3 . 8 0 \%}$ were University employed, while $\mathbf{5 6 . 5 4}$ were performing ultrasonography up to 10 hours. The prevalence of WRMDs disorder in this series was $75.17 \%$, the mean duration of symptoms was 30.48 months. $45.9 \%$ reported it as severe. WRMDs were more prevalent and severe in those doing scanning of both abdomen and Obstetric. The Low back ache is the most common site of WRMDs found in this series $(53.21 \%, n=58)$, followed by neck ache $(24.77 \%)$ wrist joint $(8.25 \%)$, finger $(7.33 \%)$ and shoulder $(6.42 \%)$. The result of bivariate analysis showed that severity of WRMDs correlated statistically significantly with primary area of expertise, duration of WRMDs, working experience and working hours.

CONCLUSION: The prevalence of WRMDs and its severity is significantly high among Sonographers of Sindh province.

KEY WORDS: Work related musculoskeletal disorder, sonographer, Ergonomic, Sindh.

This article may be cited as: Junejo MA, Tahir SM, Behan RB. Prevalence and Risk factors for Work Related Musculoskeletal Disorders among Sonographer of Sindh Province Pakistan. J Liaquat Uni Med Health Sci. 2017;16(01):29-36. doi: 10.22442/jlumhs.171610502

\section{BACKGROUND}

Work-related musculoskeletal disorders (WRMDs) is a term applied to all work related musculoskeletal pain; and is defined as "regional impairments of the muscles, tendons, nerves and joints that are associated with work-related mechanical trauma"1. The common WRMDs among medical professionals are "pain in low back, "neck, shoulder, hand, wrist, elbow, and upper back" 2 . The prevalence of WRMDs has been variably reported ranging from $80 \%{ }^{3}$ to as high as $93 \%{ }^{4}$. It has been estimated that in $20 \%$ of the cases, WRMDs among sonologists is severe enough to mandates change of the profession ${ }^{5}$.

Sonographers experience more work-related problems because ultrasound examinations involve a series of awkward repetitive movements such as: twisting the body; stretching to operate a keyboard and conduct a scan simultaneously; twisting and rotating the wrist of the hand being used for scanning; and applying a downward pressure over the scanning hand. Even more pressure is required to conduct the tests when the patient is obese. The Sonographers should maintain various tortuous and extended body positions to achieve the angles necessary to use the transducer to assess the body parts being examined. In most of the examinations, the Sonographer is required to lean across the patient's body without shoulder or elbow support to view organs on the other side of the body ${ }^{6}$.

However, no studies have been conducted in Pakistan on this vulnerable population. Pakistan is one of the countries where the practice of sonography is carried out either by a medical doctor who is trained to perform ultrasound examinations, or by a radiologist. A medical doctor who performs ultrasound is known as sonologist. In contrast to the United States and Canada, there is no separate specialty certification or registration required, to perform ultrasound 
examinations, in Pakistan. The reason may be that those involved in the ultrasound practices in Pakistan are licensed by Pakistan Medical \& Dental Council as medical doctors, having sufficient knowledge of the human sectional anatomy and patterns of various diseases, fundamental for the practice of sonography. Sonologists working in Pakistan, during training, receives inadequate or no education regarding prevention of work-related injuries and the ergonomic factors responsible for work-related injuries. The undergraduate and post graduate courses in diagnostic radiology deal primarily with the radiation hazards to the radiologist, $x$-ray technologist and other radiology workers and patients. Nothing is taught in the curriculum about the work-related musculoskeletal hazards to the sonologists or other radiology workers and preventive measures. This study by inviting participants from the Sind province of Pakistan will help explore the prevalence of work related injuries and identify some of the factors that may contribute to musculoskeletal injuries to sonologists practicing in Pakistan. To best of our knowledge this is first study of its kind in Pakistan.

Objectives: To determine the prevalence of work related musculoskeletal disorders (WRMDs) and to identify factors that may contribute to musculoskeletal disorders among sonologists of Sindh Province Pakistan.

\section{METHODOLOGY}

\section{Questionnaire}

The use of a questionnaire to identify potential ergonomic and work-related problems in the work environment is a well-established method $^{7}$. The questionnaire chosen for this study was originally designed by the Healthcare Benefit Trust, Winnipeg. This questionnaire has also been used on larger scale by British Columbia Ultra Sonographer's Association, the Health Sciences Association and the Simon Fraser University-School of Kinesiology ${ }^{8}$. We acknowledge and give credit to the Winnipeg Health Sciences Centre, Department of Occupational and Environmental Medicine for permission to use this survey tool for current research study. Considering the population sample being researched for this study, with permission few modifications in this questionnaire were done. After modification, a small pilot survey was done, by principal investigator, administering this questionnaire to two senior sonologists, to assess the language and wording, the understanding of the questions and the completion time. After few modifications done and it is anticipated that the questionnaire will take approximately 45-60 minutes to complete.

\section{Purpose and research questions}

The purpose of this research study is to know the prevalence, nature and severity of musculoskeletal work-related injuries among sonologists in the Sindh Province of Pakistan; and to identify the factor(s) that may contribute for its development and severity. It is expected that the results of this study may help to develop strategy to prevent WRMDs among sonologists.

\section{Study population}

Radiological Society of Pakistan and Ultrasound Society of Pakistan were contacted to assist with the recruitment of participants for the study. The target population chosen for this study was the sonologists from the Sind province of Pakistan, those full filled following inclusion criteria were invited for the study.

1. The registered medical doctors having ultrasound professionals' skills and working in any hospital or privately owned clinic, in the Sind Province of Pakistan.

2. The sonographers practicing at least

a) General abdominal ultrasound or

b) Gynecological and Obstetrical ultrasound or

c) Both.

3. The participant must have not been diagnosed with any of the rheumatic like disorder affecting any part of body before beginning their practice in sonography.

The exclusion criteria were:

1. Those with diagnosed rheumatic disease before or after starting professional career.

2. Those who had experienced any kind of disease which causes pain in shoulder, neck, and arm, upper or lower back before the start of their profession as sonologist.

3. Retired persons who no longer practice sonography.

4. Cardiac and Ophthalmologic Sonologists.

\section{Data collection procedures and process}

Participants were invited through mail. The envelop contained invitation letter, informed consent form, questionnaire with instructions and a stamped and pre -addressed envelope to send the consent and survey back to the researcher. The questionnaire consists of 125 questions related to the demographic, work place, work load, type of the equipment in use, questions related to type, duration, frequency and anatomical location of pain and discomfort, and ergonomic factors. Three follow up reminders on fortnightly basis were made to encourage participation.

Upon receiving the response, the questionnaire separated from the consent form, so that the names of the participant may be kept private and confidential. A letter of thanks and appreciation for participation in the study was sent to each participant by postal service. The study number on the survey forms was used for 
the input, analysis and summary of the data.

Duration \& Place of the Study: This study conducted at Department of Radiology, Liaquat University of Medical \& Health Sciences Jamshoro Pakistan from January 2014 to December 2015.

\section{Data Analysis}

SPSS software (version 16.0; SPSS Inc., USA) used to analyze the data. Demographic variables presented as mean $\pm \mathrm{SD} /$ frequency and percentages. Categorical variables were compared by using inferential of Chi-Squared analysis while continuous variables were compared using t-test statistic. To identify predictor variable for WRMDs, multiple Bivariate regression analysis was done, the level of significant was set at $P$ $<0.05$.

Conflict of Interest: None.

Source of Funding: None.

Acknowledgment: We are thankful to Mr. Marylou for granting use of questionnaire for this study.

\section{RESULTS}

\section{Demographic Data:}

A total of 230 questionnaires were distributed, 190 received while only 145 were validly complete with a response rate of $63 \%$. Male sonologists were 86 $(56.31 \%)$ and female were 59 (40.68\%); among these 145 participants' 102 were married. The commonest age group was between $40-59$ years $(53.78 \%$ ), and least common age group was less than 30 years $(9.65 \%)$ as shown in fig 1 . The mean weight and height of all respondents was $146.67 \mathrm{SD} \pm 24.86 \mathrm{Lbs}$, and165.35 $\pm 9.448 \mathrm{~cm}$.

\section{Professional Data:}

In the present study $70 \%$ of the respondents were sonologists without any qualification of radiology, while $30 \%$ were qualified radiologist. The clinical experience of all participants ranges from 0.25 to 22 years with a mean of $7.99 \mathrm{SD} \pm 4.7661$ years. More than $50 \%(53.80 \%)$ of the respondents were associated either with University or District Hospital, others were working at private clinic $(14.50 \%)$, private hospital $(11.03 \%)$ and rural health centers $(8.96 \%)$. Those sonologists working at more than one work place constituted $11.72 \%$. The respondents were engaged daily in sonography for variable time ranging from 4 hours to 12 hours. The $31.03 \%$ respondent were doing sonography daily for up to 4 hours, $27.58 \%$ for $4-8$ hours, $28.96 \%$ between $8-10$ hours and $12.41 \%$ were doing scanning for more than 10 hours. The comparison of demographic and professional data of sub-set of those reported as no WRMDs and those reported as having WRMDs is shown in table 1.

\begin{tabular}{|c|c|c|c|}
\hline & $\begin{array}{c}\text { No WRMDs } \\
(n-36)\end{array}$ & $\begin{array}{l}\text { WRMDs } \\
(n=109)\end{array}$ & P Value \\
\hline $\begin{array}{ll} & \text { Age } \\
20-30 & \\
31-40 & \\
41-50 & \\
51-60 & \end{array}$ & $\begin{array}{c}10 \\
18 \\
8 \\
-\end{array}$ & $\begin{array}{c}8 \\
30 \\
61 \\
10\end{array}$ & $\begin{array}{c}0.0141^{*} \\
0.1311^{*} \\
0.0396^{*} \\
---\end{array}$ \\
\hline Height (cm) & $\begin{array}{c}166.7779 \pm \\
4.542\end{array}$ & $\begin{array}{c}166.88 \pm \\
10.566\end{array}$ & $0.2981 \pi$ \\
\hline Weight (Lbs.) & $\begin{array}{c}147.3611 \pm \\
24.006\end{array}$ & $\begin{array}{c}146.56 \mathrm{SD} \pm \\
25.243\end{array}$ & $0.8676 \pi$ \\
\hline $\begin{array}{l}\text { Gender } \\
\text { Male } \\
\text { Female }\end{array}$ & $\begin{array}{l}26 \\
10 \\
\end{array}$ & $\begin{array}{l}60 \\
49 \\
\end{array}$ & $\begin{array}{l}0.4577^{*} \\
0.3002^{*}\end{array}$ \\
\hline $\begin{array}{l}\text { Clinical } \\
\text { Experience }\end{array}$ & $\begin{array}{c}3.7014 \\
\text { SD } \pm 1.80359 \\
(0.25-7 \text { years })\end{array}$ & \begin{tabular}{|c|}
9.4128 \\
SD \pm \\
4.58906 \\
(4-22 years) \\
\end{tabular} & $<0.0001 \uparrow$ \\
\hline \begin{tabular}{l}
\multicolumn{1}{c}{ Employment } \\
University Hospital \\
District Hospital \\
Rural Health Center \\
Private Hospital \\
Private Clinic \\
More than 1 place
\end{tabular} & $\begin{array}{c}3 \\
3 \\
9 \\
9 \\
10 \\
2\end{array}$ & $\begin{array}{l}46 \\
26 \\
04 \\
07 \\
11 \\
63\end{array}$ & $\begin{array}{l}0.0088^{*} \\
0.1434^{*} \\
0.0021^{*} \\
0.0181^{*} \\
0.0548^{*}\end{array}$ \\
\hline $\begin{array}{l}\text { Working Hours } \\
\text { Up to } 4 \text { hours } \\
\text { From } 4-8 \text { hours } \\
\text { From } 8-10 \text { hours } \\
\text { From } 10-12 \text { hours }\end{array}$ & $\begin{array}{l}22 \\
10 \\
4 \\
--\end{array}$ & $\begin{array}{l}23(31.03 \%) \\
30(27.58 \%) \\
38(28.96 \%) \\
18(12.41 \%)\end{array}$ & $\begin{array}{l}0.0040^{*} \\
0.8538^{*} \\
0.0553^{*}\end{array}$ \\
\hline
\end{tabular}

${ }^{*}=$ chi square test,$\quad \mathbb{\quad}=t$-test

Musculoskeletal symptoms:

The prevalence of WRMDs disorder in this series was $75.17 \%$ (109/145). The gender predilection showed that it was more prevalent $(55.05 \%)$ in male Sonographers as compared to female $(44.95 \%)$. The mean duration of WRMDs reported was 30.48 months (ranging from 2 to 120 months), which affects daily routine life of $64.22 \%$ Sonographer. To know the severity of pain visual analogue score (VAS) on Likert Scale from 1-10 was used, however for statistical purpose the variable was converted into ordinal as mild (1 -4), moderate (5-7) and severe (8-10). Overall the WRMDs disorder was reported as severe by $45.9 \%$, moderate by $33 \%$ and mild by $21 \%$ of the participants. Among 109 Sonographers 63 (57.80\%) sonologist with their primary responsibilities were doing scanning at other place as well for example private hospitals while $46(42.20 \%)$ were restricted to their primary assignment only. The severity of WRMDs reported as "severe" by $80 \%$ of those discharging services at more than one place and $20 \%$ reported it as moderate. 
Among those fulfilling only single assignment, none reported it as severe, $50 \%(n=13)$ reported it moderate and $50 \%(n=13)$ ranked it mild.

The $74.31 \%$ participants relate their musculoskeletal pain to work, while $25.68 \%$ considered their symptoms' unrelated to work. According to the area of expertise, the WRMDs found more prevalent $(65 \%$, $\mathrm{n}=71$ ) among those Sonographer performing scanning of both Obstetric/ Gynecological (Obs/Gynae) and abdomen; followed next in frequency $(29.35 \%, n=32)$ for those doing exclusively Gynae and Obs examination while it was least prevalent $(5.5 \%, n=6)$ for Sonographer doing examination of abdomen. The results also showed that the reported severity of WRMDs disorder is not only more prevalent but also more severe among those sonologist performing sonography both of the abdomen and Obs/Gynae. Among 50Sonographers who reported severity as severe, 38 Sonographers involved in scanning of both abdomen and Obs/Gynae examination as shown in Fig 1. Among those engaged in more than 1 working place also reported WRMDs.

The Low back ache is the most common site of WRMDs found in this series $(53.21 \%, n=58)$, followed by neck ache $(24.77 \% . n=27)$ wrist joint $(8.25 \% n=9)$, finger $(7.33 \%, n=8)$ and shoulder $(6.42 \%, n=7)$. The site of pain with respect to gender is shown in Fig 2 . The most frequently reported nature of the pain was aching (32.1\%), followed by tingling sensation (22.9\%) and sharp by $11.9 \%$. The least reported nature of pain was cramping, spastic and boring, while $8.3 \%$ were unable to exactly describe the nature of the exactly. The triggering factor for pain was variably reported by the participants. The most common triggering factor was repetitive twisting of neck and trunk (26.6\%) followed by sitting (14.7\%) and shoulder abduction $(11 \%)$. The pain was annoying enough to affect routine daily life of $56 \%(n=62)$ sonologist necessitating frequent rescheduling of routine work; $34.86 \%$ $(n=38)$ were using NSAID regularly and $14.84 \%$ $(n=14)$ were taking hot fomentation and massage as a remedy for their symptoms'. The $23.85 \%$ participants were able to take out leisure time for themselves regularly for 5-7 times/week, while other were sparing time less frequently and $45.87 \%$ were quite unable to spare time to be involve in some leisure activity.

\section{Predictor for WRMDs}

The crowding of various factors related to WRMDs and its severity is very puzzling. To identify the predictor variable(s) responsible for the severity of WRMDs, multiple Bivariate regression analysis was performed with various independent demographic and work related variables and the level of significance was set to 0.05 . The results with Pearson correlation coefficient and 2-tailed significance are shown in table no 2 . It can be predicted that severity of WRMDs disorder is more severe among those sonologist who are involved with scanning of both abdomen and Obs/ Gynae examination, working experience. The severity of WRMDs disorder correlated statistically significantly with primary area of expertise, duration of WRMDs, working experience, working hours. The WRMDs was significant enough to affect daily "off the work" quality of the life of the sonologist. As expected the severity of WRMDs disorder remained unaffected even in those sonologist performing routine physical activity as few sonologist were able to spare sufficient time to do routine physical activity.

As shown in table no 2 , the severity of WRMDs disorder increases as the experience of the sonologist and duration of WRMDs increases, it is more severe in those engaged with scanning of both abdomen and Obs/Gynae examination, working at more than one place, requiring frequent rescheduling of the work assignment yet affect routine daily life of the sonologist. It is not affected by work place and doing physical exercise.

TABLE II:

\begin{tabular}{|l|c|c|}
\hline \multicolumn{1}{|c|}{ Predictor Variable } & $\begin{array}{c}\text { Pearson's' } \\
\text { Correlation } \\
\text { Coefficient }\end{array}$ & p value \\
\hline Age & -0.110 & 0.257 \\
\hline Gender & -0.091 & 0.345 \\
\hline Present position & -0.030 & 0.758 \\
\hline Work Place & -0.126 & 0.193 \\
\hline More than one work Place & 0.819 & 0.000 \\
\hline Working Hours & -0.815 & 0.000 \\
\hline Working Experience (years) & -0.282 & 0.003 \\
\hline Physical Activity & -0.127 & 0.187 \\
\hline $\begin{array}{l}\text { Rescheduling of Working } \\
\text { hours }\end{array}$ & 0.661 & 0.000 \\
\hline Pain affect daily Living & 0.585 & 0.000 \\
\hline Duration of WRMDs & -0.357 & 0.000 \\
\hline Primary Area of Expertise & -0.236 & 0.013 \\
\hline
\end{tabular}

$P$ value (2 tail) significant at $<0.05$ 
FIGURE I:

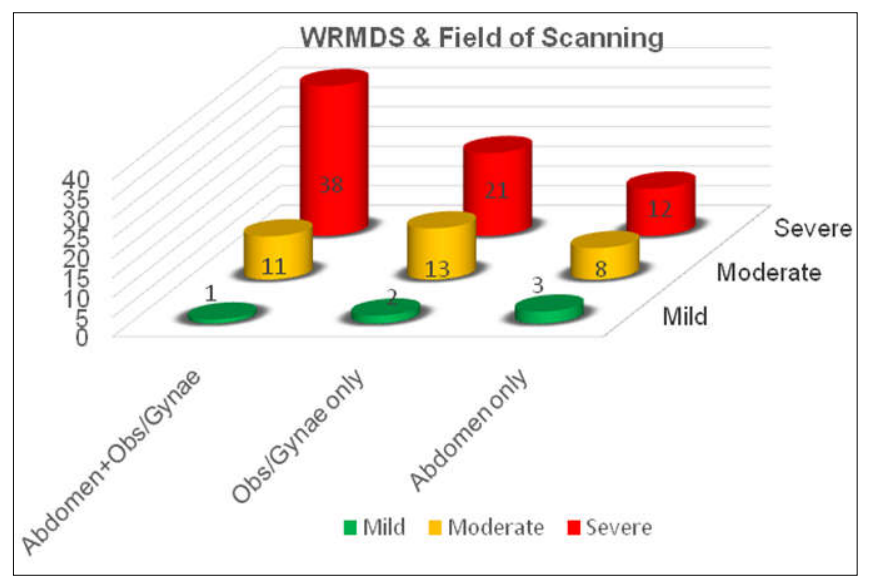

FIGURE II:

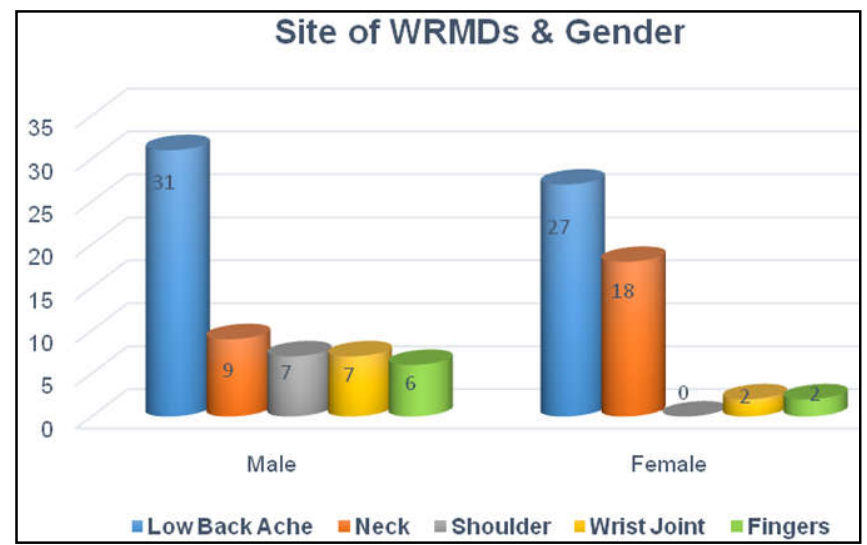

\section{DISCUSSION}

The origin of musculoskeletal pain due to work is multi -factorial. These may be considered as "predisposing (e.g. anthropometry, anxiety, job satisfaction), precipitating (e.g. trauma, long work hours), or perpetuating (e.g. poor ergonomics, poor health, fatigue, chronic pain)"9. Therefore, a study based on a questionnaire can neither adequately address nor accurately measure the "exposure-effect relationship", yet such studies are useful for epidemiological purpose and draws attention towards the problem.

The overall response rate for this study was excellent $(82.60 \%)$, which is comparable to response rate of $96 \%{ }^{10}, 93 \%{ }^{11}, 80 \%{ }^{12}$ and $76.4 \%{ }^{13}$ from internationally published literature. However, few questionnaires were not duly completely filled and finally $63.04 \%$ questionnaires were available for data analysis. It is estimated that prevalence of musculoskeletal disorders among general population is $13 \%-22 \%$, in contrast to the high prevalence of WRMDs among sonologists, ranging from $63 \%$ to $91 \%{ }^{14}$. In the present study we found prevalence of WRMDs among sonologists high as $75.17 \%$.

Among those experiencing WRMDs majority (74.31\%) were familiar with the ergonomic factor and relate their illness to work. In the current study, the height, weight and gender were compared between those having WRMDs and those reported no WRMDs as shown in table 1 , the difference was statistically insignificant which is in contrast to the study of P.A. Schulte et al ${ }^{15}$ but in agreement with other studies ${ }^{16}$. The review of the literature showed conflicting results regarding association between WRMDs with weight, height and gender. Necas Martin ${ }^{17}$ reportedthat WRMDs has no any association with weight and height, however found that female sonographer suffers more, and with marked severity than their male collogues. This is in sharp contrast to this study where we found it more prevalent among male sonographer. The probable explanation may be that in our study male Sonographers outnumber female Sonographers, while finding of Necas may be attributed to small sample size of their study. We found strong association between age, clinical experience and severity of WRMDs; a self-explanatory fact. With increasing age, experience and work load increases, however at the cost of increasing severity of WRMDs. These findings endorse results of the previous studies ${ }^{16,18}$; however, Smith et $\mathrm{al}^{19}$ had reported that there is no association between age and WRMDs among cardiac Sonographers. The results of current study showed that $65 \%(n=71)$ participants were doing scanning of both abdomen and Gynae / Obs, among these more than $50 \% \quad(n=38)$ reported WRMDs as severe. Although tight gripping of the transducer, leaning forward, repeated twisting of the wrist are required in both these subset of the patients; the perpetuating factors may be the anthropometry combine with improper or poor adjustment of the position of the sonographer for these two subsets of the patients. Scanning of full term lady may require full abduction of $120^{\circ}$ at shoulder in contrast to shoulder abduction between $30^{\circ}-60^{\circ}$ while doing scanning of abdomen. It has been estimated with shoulder abduction of $120^{\circ}$, muscles are fatigued within 5 minutes as compare to 60 minutes with shoulder abduction of $30^{\circ 20}$. Among those working at more than one place, $80 \%$ reported WRMDs as severe and $20 \%$ as moderate; this is in sharp contrast to those working at single place where none reported WRMDs as severe. Here ergonomics of the machine, examination table and chair combine with psychosocial working condition can be perpetuating factors as these may not be identical at two different work places. The objective significance of 
psychosocial work environment has recently been reported by Inger Arvidsson et $\mathrm{al}^{21}$ by studying "associations between occupational factors and musculoskeletal pain in women teachers, nurses and sonographers". They assessed workload using mechanical exposure index while psychosocial work environment was recorded using Job Content Questionnaire. They concluded that not only physical work load but also psychosocial work environment contributes significantly for development of WRMDs; although the contribution of these two varies for pain in different parts of the body. In the current study, the back ache was the most frequent site of WRMDs $(53.21 \%)$ followed by the neck ache $(24.77 \%)$ while pain affect upper limb in $22 \%$ of the sonologists. This finding is in agreement with other studies ${ }^{11,22}$ however D.E. Bassey et $\mathrm{al}^{23}$ from Nigeria reported "shoulder pain" as the most frequent site of WMSDs; and found that it could be the result of performing scan upon a couch that is above the level of the examiner's arm. The finding of the low back as most common WRMDs is not surprising as by convection in our part of the world sonographer do scanning while sitting which demands repeated forward bending, twisting or side bending of the trunk while doing examination. As most participants of the current study were employed at university hospital where hydraulic adjustable examination table are available, consequently prevalence of shoulder pain is very less in contrast to the study of $D$. E. Bassey. The perpetuating factor for back ache is trunk twist independent of the body and held in static position for long time while performing scanning in busy setup. This static position reduces blood supply however muscles do not get fatigued if only $10-15 \%$ of muscle force is applied during static position. This is impractical while scanning obese patients or doing lengthy examination. Among all participants of current study 49 were employed at tertiary care University Hospital, among these 46 reported WRMDs. This finding once again signifies the work load and lengthy examination as most patients at tertiary care needs conclusive results after scanning. These contrasting results for common site of the WRMDs can best explain by various ergonomic factors, arrangement of the work station and posture of the examiner. Contrary to the common belief that in general population low back ache is more prevalent among female; the distribution of the low back ache as WRMDs in this study was insignificant with respect to gender. However the result of this study showed neck ache is more prevalent among female sonographer when compared to male sonographer as shown in graph. The perpetu- ating factor may be the flexion, extension and protraction of the neck. The apparent cause may be the use of inappropriate position of the monitor and habit of sharing examination images with the patients. The monitor should ideally be positioned so as that examiner can look at the top of the screen. If examiner is in habit of sharing examination images with the patient than auxiliary monitor should be use. The problem has been partially resolved, new ultrasound systems are now equipped with articulated monitor that can be move into a number of different positions. University Hospital(s) are generally equipped with latest operator friendly machine, conducive environment and good working station, yet among 49 participants' employed at tertiary care University Hospital, 46 reported WRMDs. This reflect that work load also play significant role in the development/progression of WRMDs. As working conditions at different places varies significantly we analyzed data to identify predictor variable for WRMDs at our set up. The age does not correlate to the severity of WRMDs. However experience of the sonologist, duration of WRMDs, performing scanning of both abdomen and Obs/ Gynae examination and working at more than one place are significant predictors for the severity of WRMDs. Most of the sonographer reported that itis sufficiently severe necessitating frequent rescheduling of the work assignment yet affecting routine daily life adversely. No relief in severity of WRMDs reported even by those Sonographers doing some routine physical activity. The pain was annoying enough to affect routine daily life of $56 \% \quad(n=62)$ sonologist necessitating frequent rescheduling of routine work; The $38(34.86 \%)$ participants of current study having WRMDs were using self-prescribed NSAID regularly while $14(14.84 \%)$ were taking hot fomentation and massage as a remedy for their symptoms'. Although it is strongly suggested that those having WRMDs should consult with experienced health care provider $^{24}$, even in that case management has poor outcome as the person has to go back to the same environment that initiated the process ${ }^{25}$.

\section{CONCLUSION}

The prevalence of WRMDs and its severity is significantly high among Sonographers of the Sindh province of Pakistan.

\section{RECOMMENDATIONS}

The pathogenesis of WRMDs is multifactorial and therefore needs to be addressed appropriately. The preventive measure against WRMDs should be part of 
the curriculum. The work station should always be adjustable and must be adjusted appropriately to comfortable position by the operator, to minimize the risk of WRMDs and those affected should be provided best possible care.

\section{REFERENCES}

1. Bhattacharaya A, McGlothlin JD. Occupational Ergonomics Theory and Applications. $2^{\text {nd }}$ ed. New York: Marcel Dekker; 1996. p. 581.

2. Lahoti S, Narayan A, CVP Ottayil Z, Bhaskaran U. "Prevalence of musculoskeletal disorders among doctors in Mangalore: A cross-sectional survey" Int J Health Allied Sci. 2014;3(3):204-7.

3. Dodd-Hughes, K. 2008, An Evaluation of Musculoskeletal Discomfort Experienced by Sonographers, CSD HF Team report.

4. Mason Bernadette, Gregory Val. Australian Sonographers Association Publication Survey Results. Soundeffects Issue 3 2006, 12-15.

5. Brown G, Baker J. 2004, Work-related musculoskeletal disorders in sonographers.Journal of Diagnostic Medical Sonography March 2004 vol. 20 no. 2. 85-93

6. Baker JP, Coffin CT. "The importance of an ergonomic workstation to practicing sonographers". J Ultrasound Med. 2013 Aug;32 (8):1363-75. doi: 10.7863/ultra.32.8.1363.

7. Kuorinka I, Jonsson B, Kilbom A, Vinterberg $H$, Biering-Sørensen F, Andersson G, Jørgensen K. "Standardised Nordic questionnaires for the analysis of musculoskeletal symptoms". Appl Ergon. 1987 Sep;18(3):233-7.

8. Russo A, Murphy C, Lessoway V, Berkowitz J." The prevalence of musculoskeletal symptoms among British Columbia sonographers." Appl Ergon. 2002 Sep;33(5):385-93.

9. Shawn C. Roll, Lauren Selhorst, Kevin D. Evans. Contribution of Positioning to Work-Related Musculoskeletal Discomfort in Diagnostic Medical Sonographers Work. 2014 January 1; 47(2): 253260. doi:10.3233/WOR-121579.

10. A.C. Ugwu, O.A. Egwu, I.C. Nwobi and N.F. Oluware, Occupational stress among radiographers: the impact of sonography responsibility. Internet Journal of Medical Update, 4(1), 2009, 3- 6.

11. Kayode I. Oke,A. A. Adeyekun. "Patterns of Workrelated Musculoskeletal Disorders among Sonographers in selected Health Facilities in Nigeria". Journal of Applied Medical Sciences, 2

\section{(4), 2013, 67-76}

12. A. Pike, J. Russo, Berkowitz, J.P. Baker and V.A. Lessoway, The prevalence of musculoskeletal disorders and related work and personal factors among diagnostic medical sonographers. J Diag Medical Sonography, 13(5), 1997, 219- 227.

13. N. Magnavita, L. Bevilacqua, P. Mirk, A. Fileni and N. Castellino, Work-related musculoskeletal complaints in sonologists. J Occup Environ Med. 41(11), 1999, 981-988.

14. Rousseau T, Mottet N, Mace G, Franceschini C, Sagot P. "Practice Guidelines for Prevention of Musculoskeletal Disorders in Obstetric Sonography". J Ultrasound Med 2013; 32:157-164

15. P.A. Schulte, G.R. Wagner, A. Ostry, L.A. Blanciforti, R.G. Cutlip et. al., Work, Obesity, and Occupational Safety and Health. Am J Public Health, 97(3), 2007, 428-36.

16. N. Magnavita, L. Bevilacqua, P. Mirk, A. Fileni and N. Castellino, Work-related musculoskeletal complaints in sonologists. J Occup Environ Med. 41(11), 1999, 981-988.

17. Martin N. "Musculoskeletal Symptomatology and Repetitive Strain Injury in Ultrasonographers: A Pilot Study in Washington and Oregon". Journal of Diagnostic Medical Sonography. 1996; 12(6): 266273.

18. Horkey J, King P. Ergonomic recommendations and their role in cardiac sonography. Work,2004; 22(3):207-8.

19. Smith AC, Wolf JG, Xie GY, Smith MD. Musculoskeletal pain in cardiac ultrasonographers: results of a random survey. J Am Soc Echocardiogr.1997;10(4):357-62.

20. Brown G, Baker J. Work-Related Musculoskeletal Disorders in Sonographers. Journal of Diagnostic Medical Sonography. 2004; 20(2):85-93.

21. Arvidsson I, Simonsen JG, Dahlqvist C, Axmon A, Karlson B, et al. Cross-sectional associations between occupational factors and musculoskeletal pain in women teachers, nurses and sonographers. BMC Musculoskeletal Disorders 2016, 17:35. DOI 10.1186/s12891-016-0883-4

22. N.K. Irurhe, U.A.C. Okafor, O.O Adekola, D.O. Odebiyi, M.Y.M. Habeebu, A.C. Sowunmi. Work Related Musculoskeletal Discomforts (WRMD) in Ultrasonologists: Prevalence and Risk Factors. WJMS.2013;8(3):199-204.

23. AO Akintomide DE Bassey, D.U. Eduwem, G.U. 
Inah, A. Udoaka. Work Related Musculoskeletal Disorder amongst Sonologists In Nigeria. IOSRJDMS. 2013;10(2): 68-71.

24. Dodgeon J, Bernard F, Wilde J. Avoidance of musculoskeletal disorders during ultrasound scanning. Sound Ergonomics. LLC 2008. 1.

25. Gibbs V. Young P. Work related musculoskeletal disorders in sonography and the Alexander Technique. Ultrasound. 2008;16(14): 213-9.

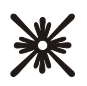

AUTHOR AFFILIATION:

Prof. Muneer Ahmed Junejo

Department of Radiology

Liaquat University of Medical \& Health Sciences

(LUMHS), Jamshoro, Sindh-Pakistan.

Dr. Syed Muhammad Tahir (Corresponding Author)

Department of Burn/Plastic Surgery

LUMHS, Jamshoro, Sindh-Pakistan.

E mail: smtahir@lumhs.edu.pk

Dr. Rasool Bux Behan

Assistant Professor, Department of Surgery

LUMHS, Jamshoro, Sindh-Pakistan. 